\title{
Association of telomerase reverse transcriptase promoter mutations with clinicopathological features and prognosis of thyroid cancer: a meta-analysis
}

\author{
This article was published in the following Dove Press journal: \\ OncoTargets and Therapy \\ II November 2016 \\ Number of times this article has been viewed
}

\section{Xingyun $\mathrm{Su}^{\prime}$ \\ Xiaoxia Jiang' \\ Weibin Wang' \\ Haiyong Wang' \\ $\mathrm{Xin} \mathrm{Xu}^{2}$ \\ Aihui Lin' \\ Xiaodong Teng ${ }^{3}$ \\ Huiling $\mathrm{Wu}^{4}$ \\ Lisong Teng'}

'Department of Surgical Oncology, ${ }^{2}$ Department of Medical Oncology,

${ }^{3}$ Department of Pathology,

${ }^{4}$ Department of Plastic Surgery,

First Affiliated Hospital, School of Medicine, Zhejiang University, Hangzhou, Zhejiang, People's Republic of China
Correspondence: Lisong Teng

Department of Surgical Oncology, First Affiliated Hospital, School of Medicine, Zhejiang University, 79 Qingchun Road, Hangzhou 310003, Zhejiang, People's

Republic of China

Tel +86 57| 87236878

Fax +86 57I 87236734

Email Isteng@zju.edu.cn

\begin{abstract}
The clinicopathological and prognostic significance of telomerase reverse transcriptase (TERT) promoter mutations have been widely investigated in thyroid cancer; however, the results are still discrepant. Systematic searches were performed in PubMed, Web of Science, Scopus, Ovid, and the Cochran Library databases for relevant articles prior to April 2016. Mutation rates were synthesized by $\mathrm{R}$ statistical software. The odds ratio or standardized mean difference with $95 \%$ confidence interval was pooled by Stata. A total of 22 studies with 4,907 cases were included in this meta-analysis. TERT promoter mutations tended to present in aggressive histological types including poorly differentiated thyroid cancer $(33.37 \%)$, anaplastic thyroid cancer $(38.69 \%)$, and tall-cell variant papillary thyroid cancer $(30.23 \%)$. These promoter mutations were likely to exist in older patients and males and were well associated with larger tumor size, extrathyroidal extension, vascular invasion, lymph node metastasis, distant metastasis, advanced tumor stage, disease recurrence/persistence, and mortality. In addition, TERT promoter mutations (especially $\mathrm{C} 228 \mathrm{~T}$ ) tended to coexist with $B R A F^{\mathrm{V} 600 \mathrm{E}}$ mutation, which indicated more aggressive tumor behavior. Therefore, TERT promoter mutations may be promising biomarkers for early diagnosis, risk stratification, prognostic prediction, and management of thyroid cancer.
\end{abstract}

Keywords: TERT promoter mutations, thyroid cancer, clinicopathological features, prognosis, $B R A F^{\mathrm{V} 600 \mathrm{E}}$ mutation

\section{Introduction}

Telomerase, a RNA-dependent DNA polymerase, adds repeat segments to the end of linear chromosomes stabilizing the length of telomere and enabling the immortalization of malignant cells. ${ }^{1}$ Telomerase reverse transcriptase (TERT) is a rate-limiting catalytic subunit of telomerase complex taking part in telomerase reactivation and telomere elongation. ${ }^{2,3}$ Overexpression of TERT and activation of telomerase are found in various malignancies, which are linked to cancer hallmarks including proliferation, antiapoptosis, angiogenesis, invasion, and metastasis. ${ }^{4,5}$ Two mutations in -124 bp (chr5: 1,295,228; termed C228T) and -146 bp (chr5: 1,295,250; termed C250T) upstream from the translation start site of TERT gene have been identified in melanomas ${ }^{6,7}$ and have further been found in glioma, ${ }^{8,9}$ liposarcoma, ${ }^{9}$ urothelial carcinoma, ${ }^{8,10}$ hepatocellular carcinoma, ${ }^{8,11}$ and thyroid cancers. ${ }^{12-17}$ Functional research studies showed that TERT promoter mutations enhanced the transcriptional activity of the TERT promoter, which highly upregulated the mRNA level and increased telomerase activity. ${ }^{8}$ 
This may be because both mutations generate novel binding sites (GGAA/T) for E-twenty-six (ETS) transcription factors and enhance the transcriptional level, which provides an alternative mechanism of TERT activation. ${ }^{6-8}$

Thyroid cancer is the most common endocrine malignancy, with an increasing incidence in the last few decades. ${ }^{18,19}$ Among the follicular-cell-derived thyroid cancer (FCDTC), papillary thyroid cancer (PTC) and follicular thyroid cancer (FTC) are well-differentiated and classified as differentiated thyroid cancer (DTC), ${ }^{20}$ while anaplastic thyroid cancer (ATC) is undifferentiated with limited survival of $<6$ months. ${ }^{21}$ Another rare histological type is medullary thyroid cancer (MTC) originating from parafollicular or C cells. Development and progression of thyroid cancer are accompanied by accumulation of genetic and epigenetic alterations which vary from different histological types of thyroid cancer. The aberrant activation of RET signaling is the primary mechanism of MTC, while MAPK pathway (mainly triggered by $B R A F^{\mathrm{V} 600 \mathrm{E}}$ mutations) and $\mathrm{PI} 3 \mathrm{~K}$ pathway (which can be caused by mutations in RAS, PTEN, and $P I K 3 C A$ ), respectively, lead to PTC and FTC. ${ }^{20}$ TERT promoter mutations also participate in the carcinogenesis of thyroid cancer, and the frequency ranges from $9 \%$ to $37 \%$ in different studies. ${ }^{12-14,16,17,22}$ Although the clinicopathological and prognostic significance of TERT promoter mutations have been investigated in various research studies, ${ }^{14-17,22,23}$ no consistent conclusion has been achieved. ${ }^{15,24-26}$ Besides, some researchers have reported that the coexistence of $B R A F$ and TERT promoter mutations contributes to more aggressive tumor and worse outcome; ${ }^{15,23,27}$ however, other researchers have reported contrary results. ${ }^{24,28}$

Therefore, this meta-analysis was conducted to clarify the distribution of TERT promoter mutations in different histological types of thyroid cancer and then analyze their association with high-risk clinicopathological features, adverse outcomes, and $B R A F^{\mathrm{V} 600 \mathrm{E}}$ mutation. Furthermore, the practical values of TERT promoter mutations in preoperative diagnosis, risk stratification, prognostic prediction, and therapeutic option were evaluated.

\section{Materials and methods}

\section{Search strategy and selection criteria}

Systematic searches were performed in PubMed, Web of Science, Scopus, Ovid, and the Cochran Library databases for relevant studies before April 2016. The search terms were: ((thyroid cancer) or (thyroid neoplasm) or (thyroid tumor)) and ((TERT) or (telomerase reverse transcriptase)). Relevant articles and reviews were also inspected for additional studies. Studies were included according to the following criteria: 1) detecting TERT promoter mutations in thyroid cancer; 2) data availability of mutation rate, clinicopathological features, prognosis, or $B R A F^{\mathrm{V} 600 \mathrm{E}}$ mutation; and 3) evaluation of the summary odds ratio (OR) or standardized mean difference (SMD) with $95 \%$ confidence interval (CI). Studies were excluded based on these criteria: 1) review, case report, editorial, or comments; and 2) research studies with repeated or unusable data.

\section{Data extraction and quality assessment}

Details including first author, year of publication, country, number of centers, study design, number of participants, histological type of thyroid cancer, mean age, gender, sample source, sequencing method, cases and duration of follow-up, $B R A F^{\mathrm{v} 600 \mathrm{E}}$ mutation, clinicopathological features (mean diameter of tumor, extrathyroidal extension, vascular invasion, distant metastasis, lymph node metastasis, and tumor stage), and adverse outcome (persistence/ recurrence and disease specific mortality) were obtained from the studies. Tumor stage was standardized by the tumor-node-metastasis (TNM) system of the American Joint Committee on Cancers. ${ }^{25}$ Persistence/recurrence was defined as the presence of abnormality confirmed by pathology. The quality of studies was assessed by two investigators according to the Newcastle-Ottawa scale (NOS) comprising three dimensions: four scores for subject selection, two scores for subject comparability, and three scores for prognostic assessment. ${ }^{26}$ Studies with $>7$ scores were regarded as high quality, 4-6 scores were mid-range, and $\leq 3$ were low quality.

\section{Statistical analysis}

Mutation frequencies were synthesized by R statistical software (version 3.2.1; R Foundation for Statistical Computing, Vienna, Austria). OR and SMD, respectively, quantify the association between TERT promoter mutations and dichotomous variables (gender, extrathyroidal extension, vascular invasion, lymph node metastasis, distant metastasis, stage, recurrence/persistence, mortality, and $B R A F^{\mathrm{V} 600 \mathrm{E}}$ mutation) and continuous variables (age and tumor size). Pooled OR and SMD with 95\% CI were achieved by STATA (version 12.0; Stata Corporation, College Station, TX, USA). The potential heterogeneity was evaluated by Cochrane Q test and inconsistency index $\left(I^{2}\right) . I^{2}>50 \%$ suggested significant heterogeneity and so random effects model (DerSimonianLaird method) was chosen; otherwise, fixed effects model (Mantel-Haenszel method) would be considered..$^{29}$ Continuous data were pooled by Cohen method for SMD when the 
number of studies $>10$ (both fixed effects model and random effects model). For all analyses, $P<0.05$ was regarded as statistically significant.

\section{Results}

\section{Search results and quality assessment}

A flowchart of the literature research is shown in Figure 1. A total of 1,106 articles were initially included. After removal of the duplicates, 894 studies remained. Then, 854 studies were excluded after reviewing the titles and abstracts. Fulltext of the remaining 40 studies were further evaluated, and 22 studies with 4,907 patients were ultimately included in this meta-analysis. ${ }^{12-17,22,23,27,30-42}$ All the 22 studies reported the frequency of TERT promoter mutations, ${ }^{12-17,22,23,27,30-42}$ 18 studies were available for analyzing the clinicopathological features and prognostic significance, ${ }^{14-17,22,23,27,31-33,35-42}$ 15 studies investigated the relationship of TERT promoter and $B R A F^{\mathrm{V} 600 \mathrm{E}}$ mutations, ${ }^{13,15,16,22,23,27,33-37,39-42}$ and six of them evaluated the synergetic effect of both mutations. ${ }^{15,24,25,35,37,41}$ According to the NOS system, 11 studies were classified as high-quality and the other 11 were mid-range. Main characteristics and methodological quality of all the 22 studies are listed in Table 1 according to the publication year. The structures of TERT core promoter and BRAF protein kinase are shown in Figure 2.

\section{Distribution of TERT promoter mutations in thyroid cancer}

Table 2 summarized the distribution of TERT promoter mutations in different histological types of thyroid cancer.
Random effects model was used in the analysis with obvious heterogeneity $\left(R^{2}>50 \%\right)$; otherwise, the fixed effects model was chosen. The TERT promoter mutations only existed in FCDTC, but were absent in MTC and benign lesions (data not shown). Two types of TERT promoter mutation (C228T and C250T) were mutually exclusive. Besides, C228T (0.1126; 95\% CI $0.0820-0.1433)$ was more common than C250T (0.0271; 95\% CI $0.0174-0.0368)$. Their frequencies in poorly differentiated thyroid cancer (PDTC) $(0.3337$; 95\% CI 0.2068-0.4606) and ATC $(0.3869 ; 95 \%$ CI $0.2866-0.4872)$ were three times higher than that in DTC $(0.1091 ; 95 \%$ CI $0.0819-0.1363)$. And the rate in FTC $(0.1703$; 95\% CI $0.1277-0.2128)$ was nearly twice in PTC $(0.0941 ; 95 \%$ CI 0.0716-0.1165). Among the subcategories of PTC, tall-cell PTC (TCPTC, 0.3023; 95\% CI $0.1650-0.4396)$ harbored especially higher rate than conventional $(0.0342$; 95\% CI 0.0362-0.1490) and follicular variant (0.0809; 95\% CI 0.0207-0.1824) PTCs.

\section{Clinicopathological and prognostic significance of TERT promoter mutations}

Age, gender, tumor size, extrathyroidal extension, vascular invasion, lymph node metastasis, distant metastasis, tumor stage, persistence/recurrence, and mortality were obtained from the studies $11,16,7,8,4,14,8,12,8$, and 5, respectively. Fixed effects model was used in the analysis of gender, vascular invasion, persistence/recurrence, and mortality, while random effects model was chosen for the other analyses.

As shown in Figure 3, TERT promoter mutations tended to present in older patients (SMD 0.79; 95\% CI 0.61-0.96)

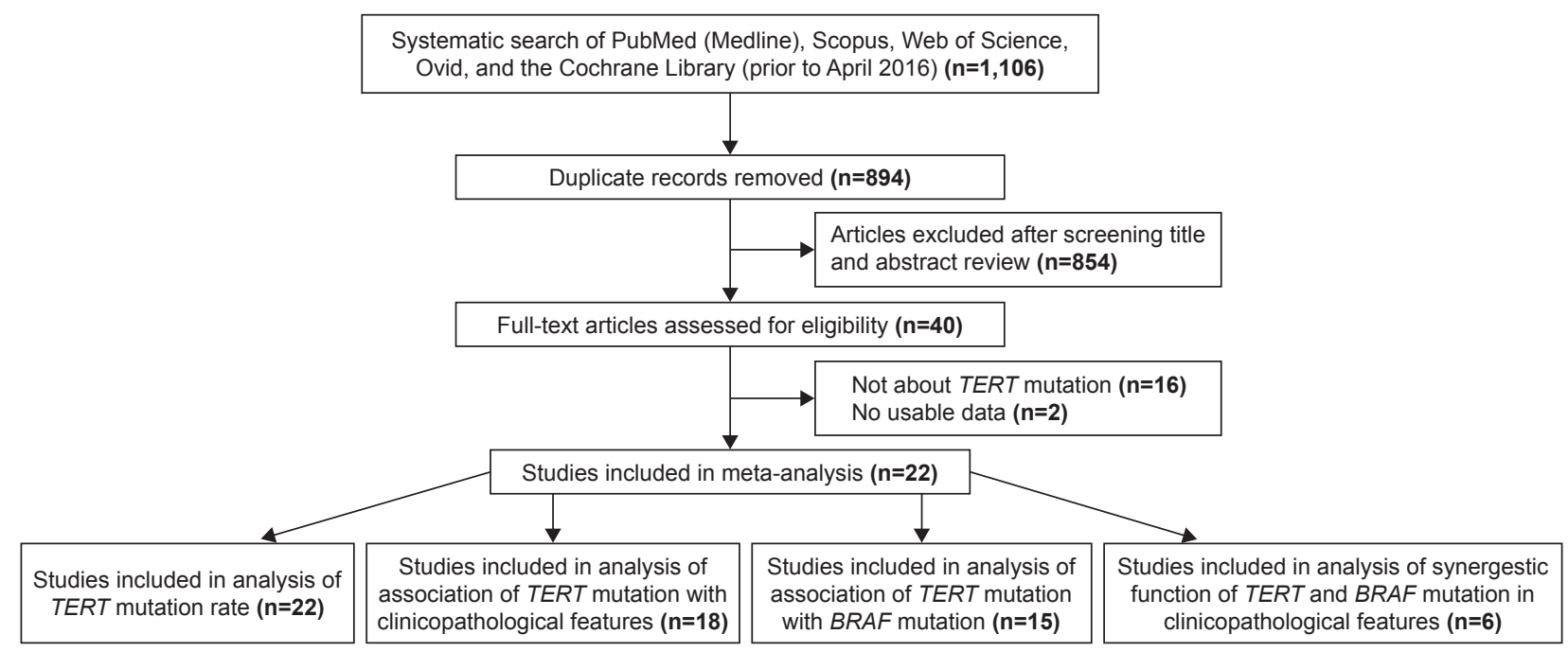

Figure I Flowchart of study selection process. Abbreviation: TERT, telomerase reverse transcriptase. 


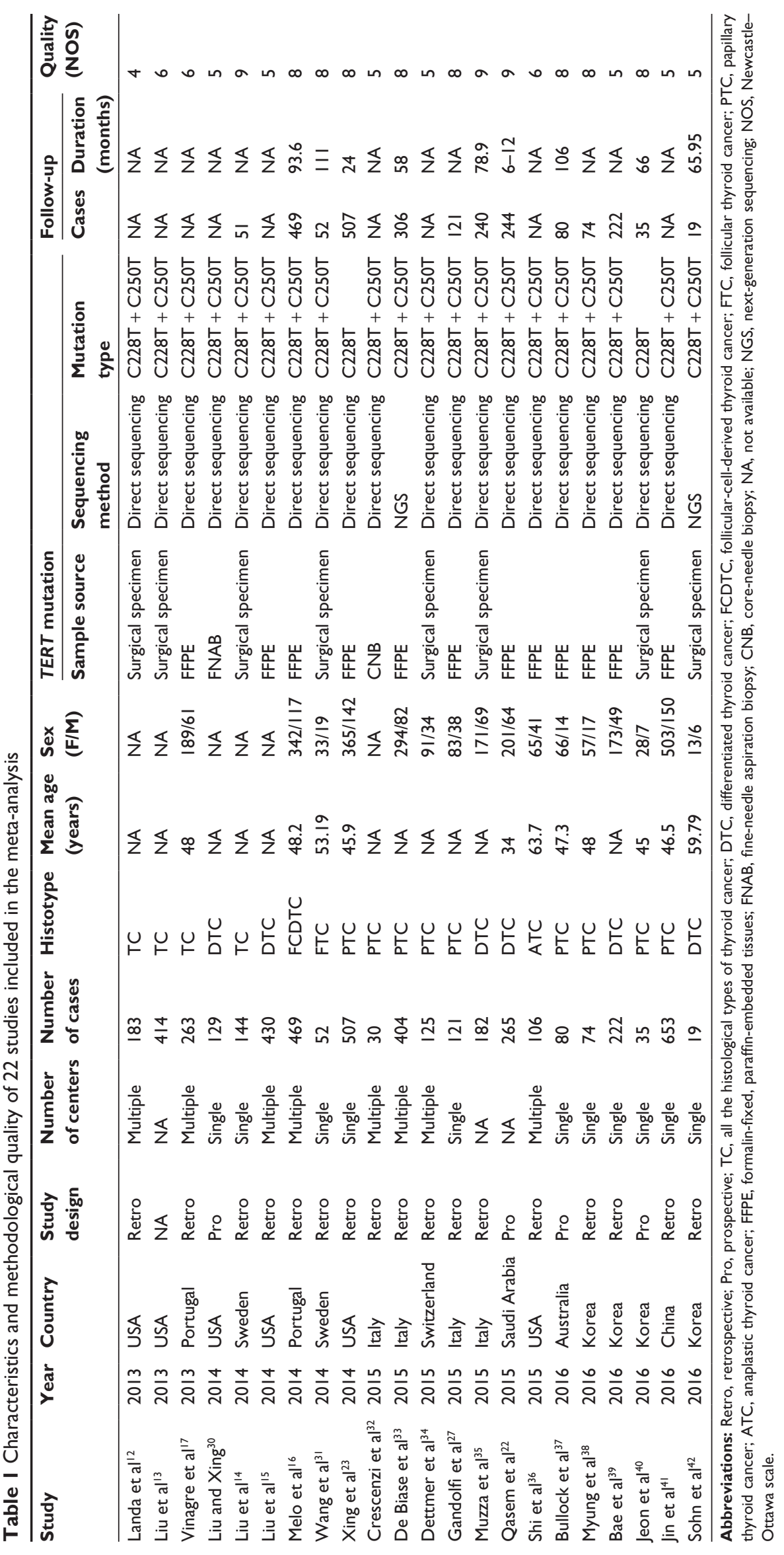




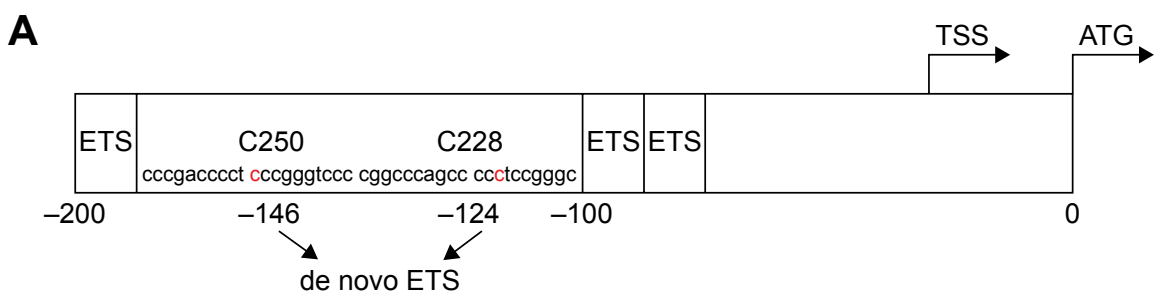

B

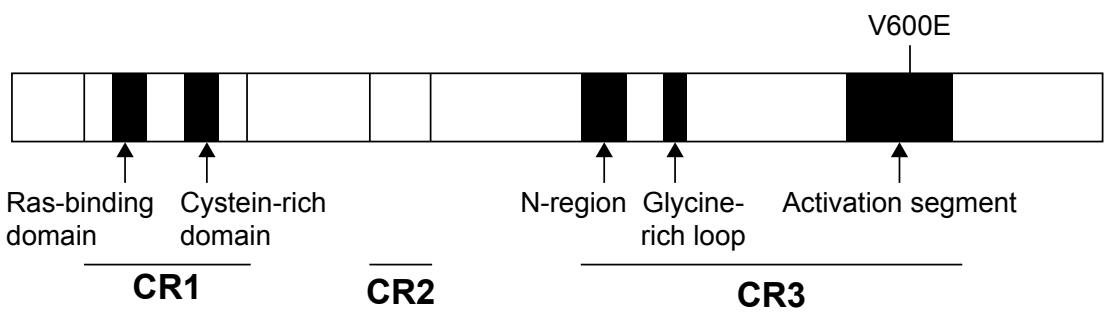

Figure 2 Schematic representation of TERT core promoter and BRAF protein kinase.

Notes: (A) The C228T and C250T mutations are located in -124 bp and -146 bp upstream from the TSS, which induce novel ETS binding sites. (B) There were three conserved regions (CRI, 2, 3) in the BRAF protein kinase. CRI and CR2 are regulatory domains and CR3 is the catalytic domain. RBD and CRD are located in CRI. The $\mathrm{N}$-region, glycine-rich loop, and activation segment are located in CR3. BRAF ${ }^{\mathrm{V} 600 \mathrm{E}}$ is located in the activation segment.

Abbreviations: TERT, telomerase reverse transcriptase; TSS, translation start site; ETS, E-twenty-six; RBD, Ras-binding domain; CRD, cystein-rich domain.

and males (OR 1.64; 95\% CI 1.31-2.05). Besides, they were relevant to larger tumor size (SMD 0.67; 95\% CI 0.31-1.04), extrathyroidal extension (OR 2.86; 95\% CI 1.68-4.86), vascular invasion (OR 1.81; 95\% CI 1.22-2.68), lymph node metastasis (OR 1.80; 95\% CI 1.11-2.91), distant metastasis (OR 8.19; 95\% CI 4.11-16.32), and advanced tumor stage (OR 5.39; 95\% CI 2.90-10.00). They also indicated adverse outcomes including tumor persistence/recurrence (OR 3.75; 95\% CI 2.58-5.45) and disease-related mortality (OR 8.39; 95\% CI 4.13-17.03).

\section{Relationship of TERT promoter and $B R A F^{\mathrm{V} 600 \mathrm{E}}$ mutations}

As shown in Figure 4, TERT promoter mutations were likely to occur in $B R A F^{\mathrm{V} 600 \mathrm{E}}$-positive thyroid cancer (OR 1.88; 95\% CI 1.41-2.51), which was especially obvious in C228T (OR 2.53; 95\% CI 1.77-3.62) rather than C250T mutation (OR 0.64; 95\% CI 0.13-3.06). Random effects model was used to evaluate the association between $B R A F^{\mathrm{V} 600 \mathrm{E}}$ and C250T mutations.

Patients harboring both TERT promoter and $B R A F^{\mathrm{V} 600 \mathrm{E}}$ mutations tended to be male (OR 3.71; 95\% CI 1.66-8.29) and have larger tumor size (SMD 0.80; 95\% CI 0.24-1.35), extrathyroidal extension (OR 5.85; 95\% CI 2.14-16.01), and advanced tumor stage (OR 7.90; 95\% CI 3.22-19.37) in comparison with patients with TERT promoter mutations only (Table 3 ). When compared with patients having $B R A F^{\mathrm{V} 600 \mathrm{E}}$ mutation only, patients harboring both TERT and $B R A F^{\mathrm{V} 600 \mathrm{E}}$ mutations seemed to be older patients (SMD 0.77; 95\% CI 0.40-1.15) and males (OR 2.38;
95\% CI 1.59-3.56) and tended to suffer from extrathyroidal extension (OR 5.76; 95\% CI 3.45-9.63), lymph node metastasis (OR 1.58; 95\% CI 1.01-2.47), distant metastasis (OR 13.07; 95\% CI 2.57-66.59), advanced tumor stage (OR 4.22; 95\% CI 2.71-6.58), recurrence/persistence (OR 8.50; 95\% CI 4.20-17.19), and mortality (OR 8.14; 95\% CI 2.38-27.89) (Table 3).

\section{Discussion}

The majority of thyroid cancer has excellent prognosis after thyroidectomy with/without radioiodine ablation. ${ }^{43}$ However, a small group of patients suffer from unfavorable outcome. ${ }^{44,45}$ During the pathogenesis and progression of thyroid cancer, a number of genetic and epigenetic alterations are accumulated. These alterations provide potential biomarkers to discriminate aggressive cases from those with indolent behavior. In recent years, the clinicopathological and prognostic significance of TERT promoter mutations have been widely evaluated in thyroid cancer, and the discrepancies among studies are probably caused by small sample size of individual studies. ${ }^{14-17,22,23}$ This meta-analysis demonstrated that TERT promoter mutations were likely to aggregate in aggressive histological types and associated with high-risk clinicopathological features and adverse outcome of thyroid cancer. The present study also confirmed the coexistence of TERT promoter (C228T) and $B R A F^{\mathrm{V} 600 \mathrm{E}}$ mutations, which contributed to more aggressive tumor behavior. De-Tao et al conducted a similar metaanalysis recently, but it only included 8 studies comprising 2,035 patients and excluded studies analyzing fine-needle aspiration biopsy (FNAB) which was an important and 


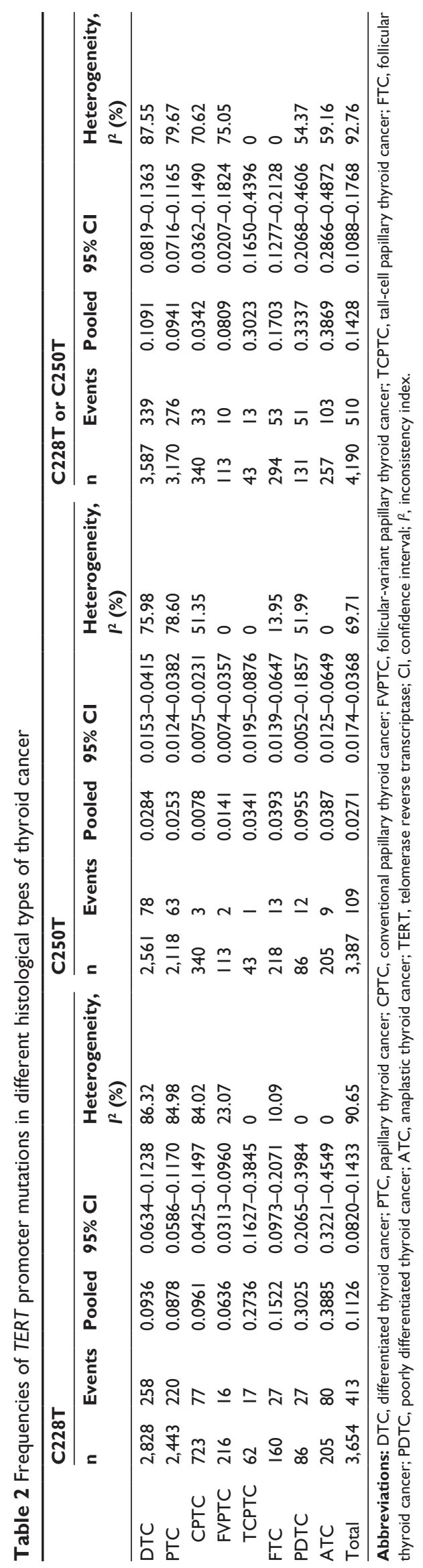

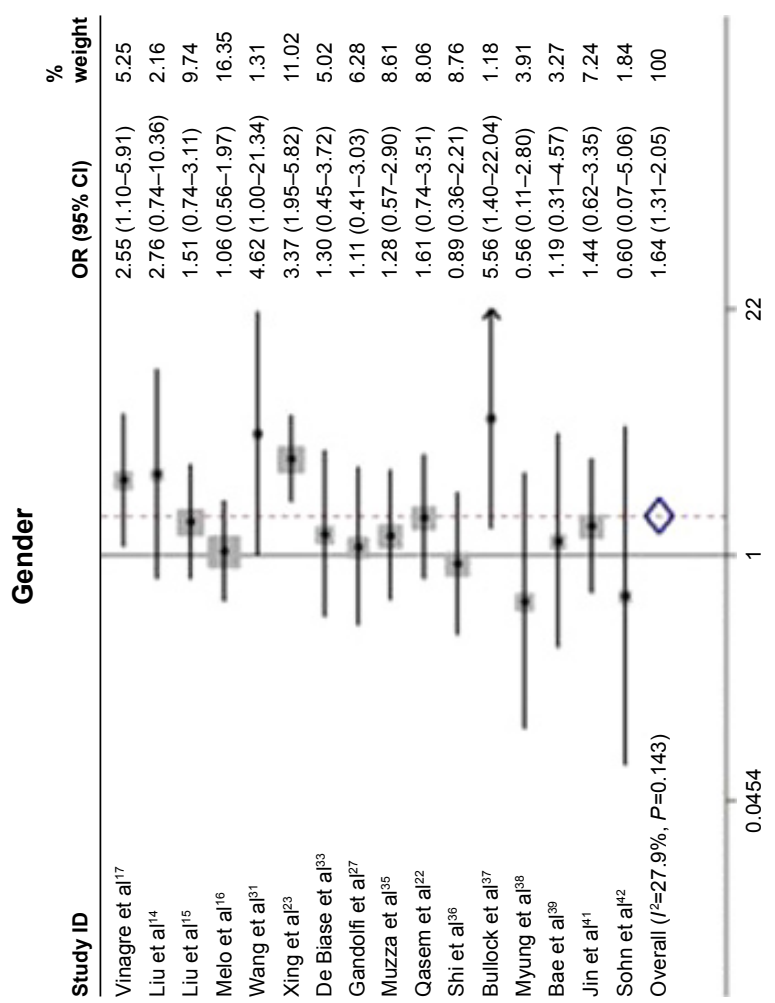

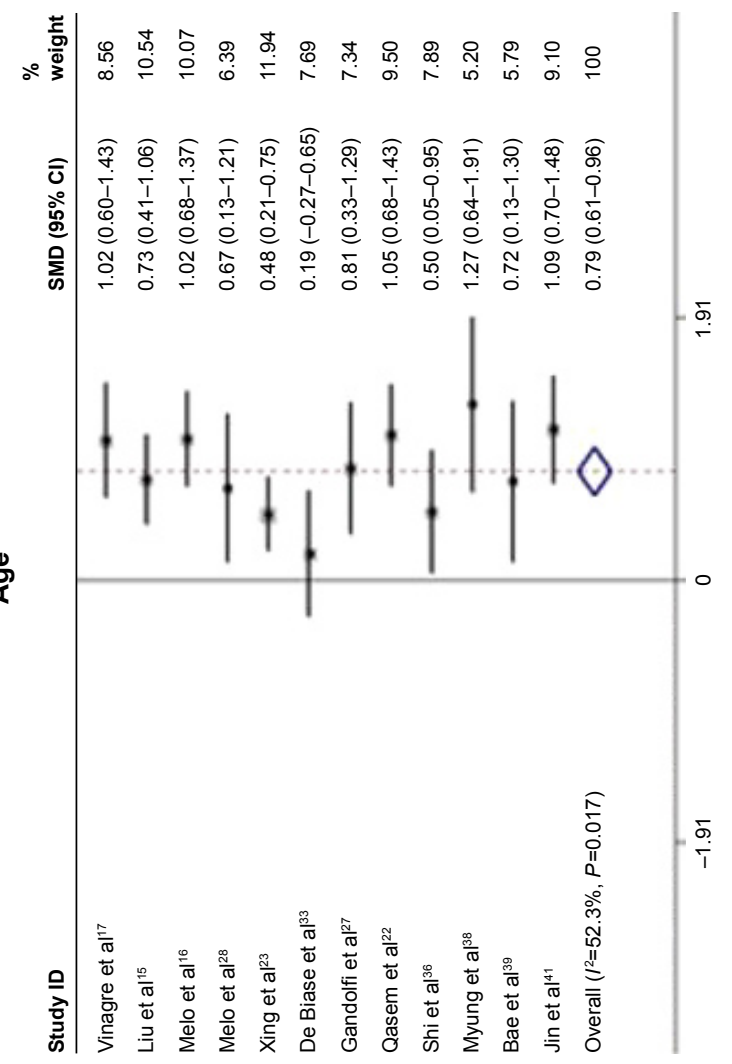




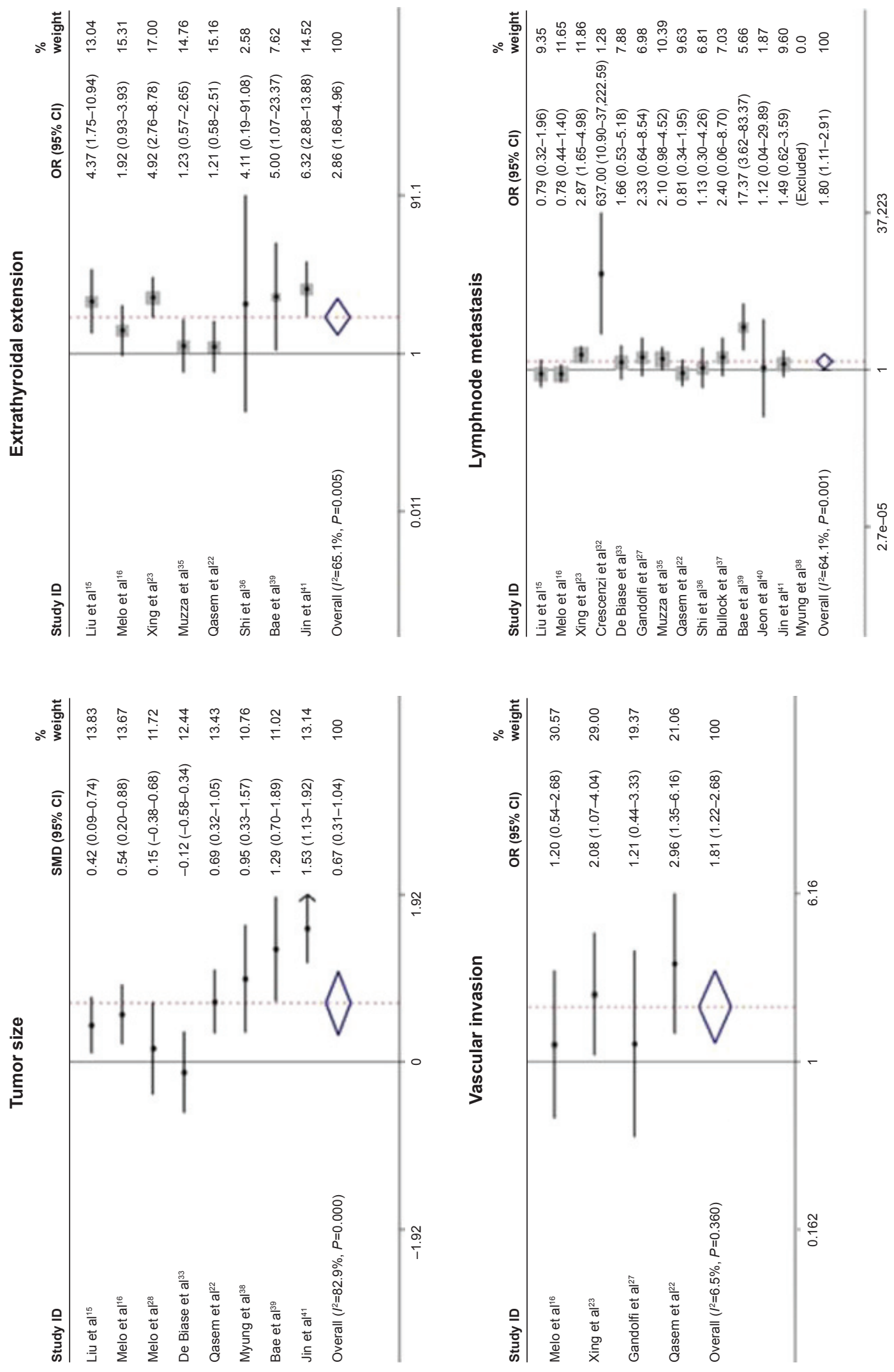

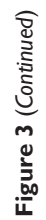



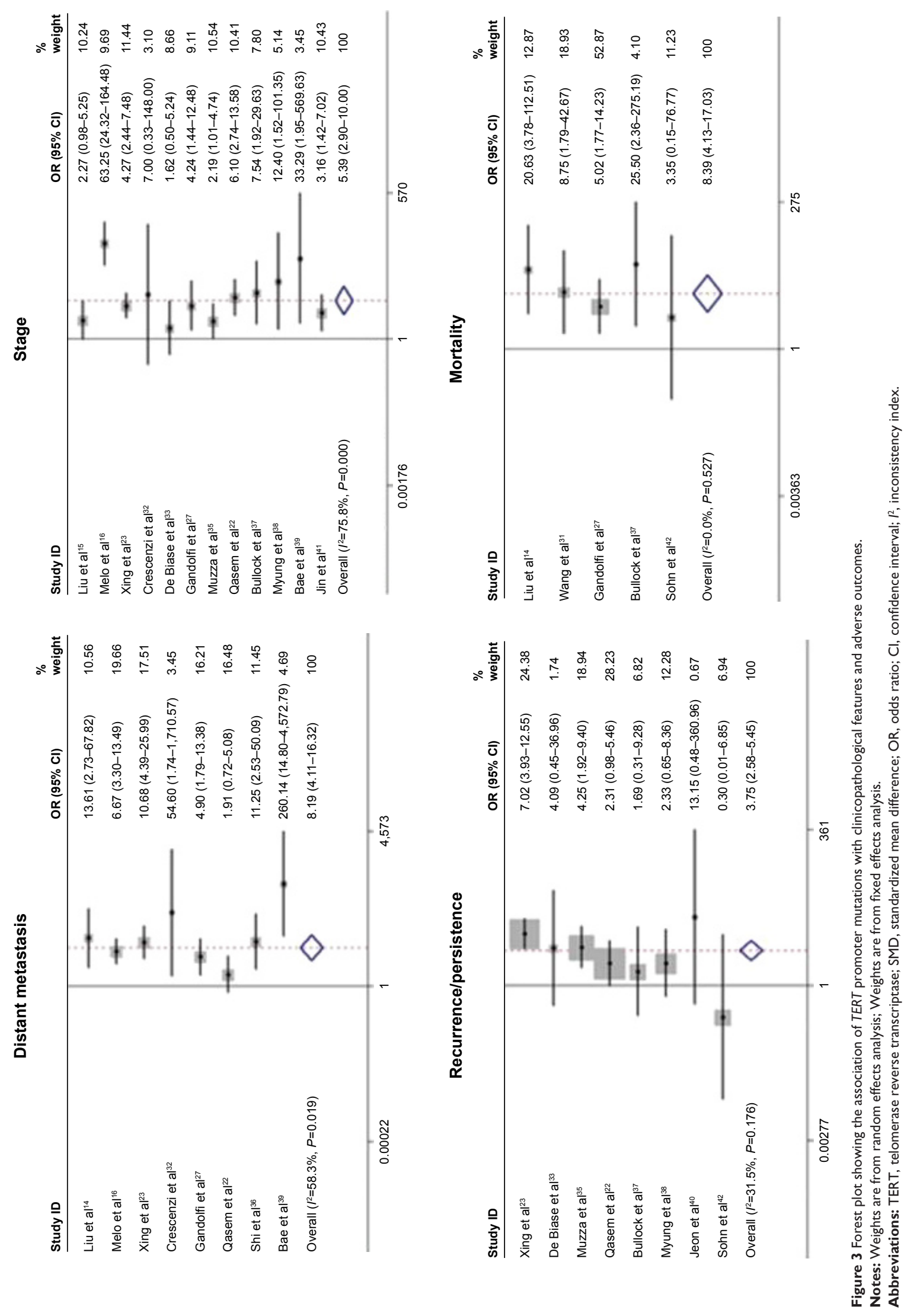


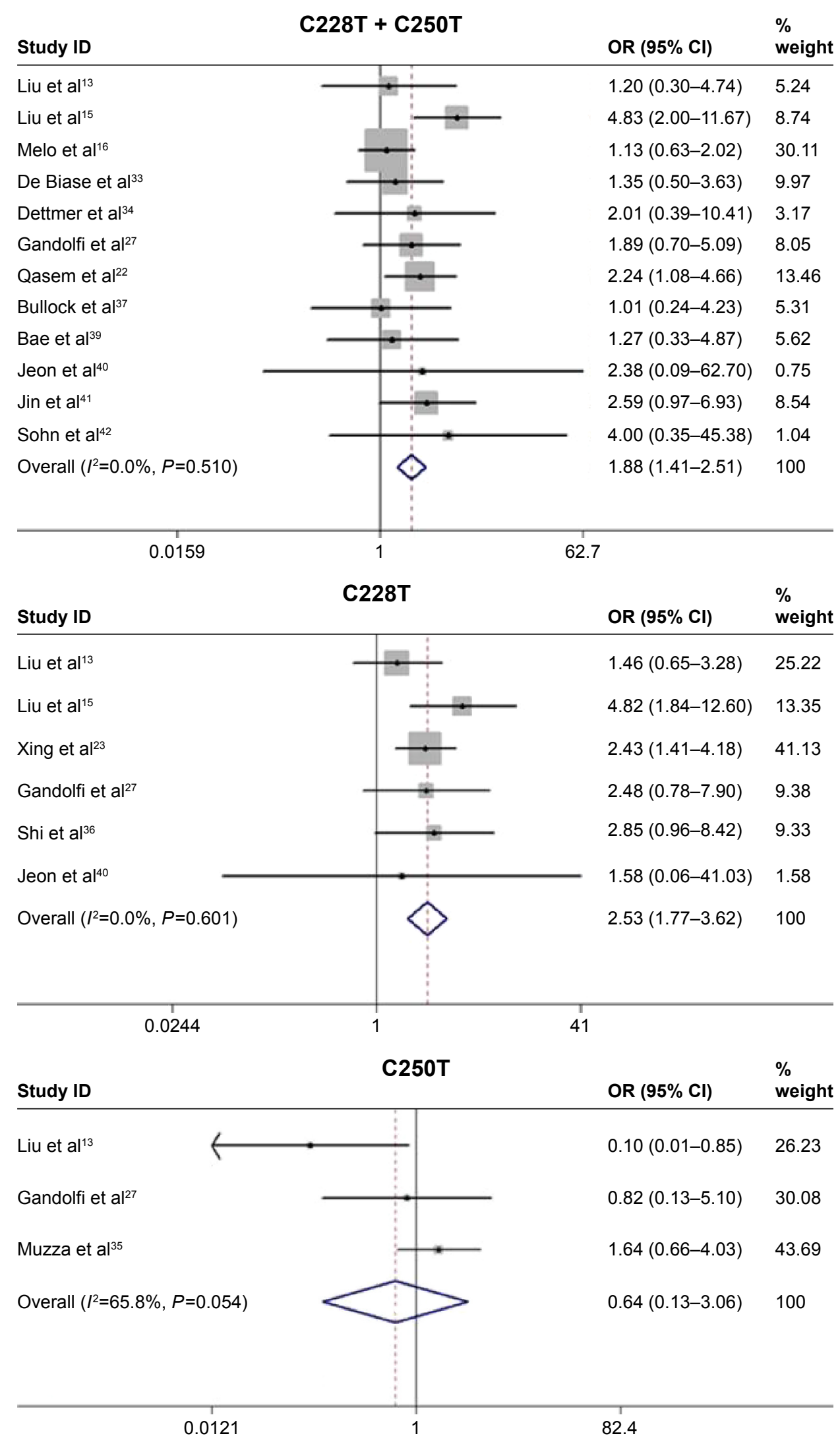

Figure 4 Forest plot showing the relationship of TERT promoter mutations and BRAF mutation.

Note: Weights are from random effects analysis.

Abbreviations: TERT, telomerase reverse transcriptase; OR, odds ratio; $\mathrm{Cl}$, confidence interval; $I^{2}$, inconsistency index. 
Table 3 The synergetic effect of TERT promoter and BRAF mutations in clinicopathological features and adverse outcomes

\begin{tabular}{|c|c|c|c|c|c|c|c|}
\hline \multirow[t]{2}{*}{ Variable } & \multirow{2}{*}{$\begin{array}{l}\text { No of } \\
\text { studies }\end{array}$} & \multicolumn{3}{|c|}{ TERT + BRAF vs TERT } & \multicolumn{3}{|c|}{ TERT + BRAF vs BRAF } \\
\hline & & $\begin{array}{l}\text { No of } \\
\text { cases }\end{array}$ & OR (95\% Cl) & $\begin{array}{l}\text { Heterogeneity, } \\
I^{2}(\%)\end{array}$ & $\begin{array}{l}\text { No of } \\
\text { cases }\end{array}$ & OR (95\% Cl) & $\begin{array}{l}\text { Heterogeneity, } \\
I^{2}(\%)\end{array}$ \\
\hline Age & 5 & 170 & $0.43(-0.18-1.03)$ & 61.8 & $\mathrm{I}, 12 \mathrm{I}$ & $0.77(0.40-1.15)$ & 70.2 \\
\hline Gender & 5 & 170 & $3.71(1.66-8.29)$ & 0 & 705 & $2.38(1.59-3.56)$ & 38.0 \\
\hline Tumor size & 3 & 88 & $0.80(0.24-1.35)$ & 0 & 873 & $0.69(-0.26-1.64)$ & 92.6 \\
\hline Extrathyroidal extension & 3 & 108 & $5.85(2.14-16.01)$ & 16.6 & 759 & $5.76(3.45-9.63)$ & 0 \\
\hline Vascular invasion & 2 & 73 & $0.57(0.10-3.39)$ & 57.5 & 223 & 0.57 (0.097-3.39) & 0 \\
\hline Lymph node metastasis & 5 & 125 & $2.08(0.97-4.49)$ & 0 & 646 & $1.58(1.0 \mathrm{I}-2.47)$ & 0 \\
\hline Distant metastasis & 2 & 82 & $1.47(0.13-16.82)$ & 73.1 & 248 & |3.07 (2.57-66.59) & 58.7 \\
\hline Stage & 5 & 150 & $7.90(3.22-19.37)$ & 0 & 1,032 & $4.22(2.7 \mathrm{I}-6.58)$ & 25.8 \\
\hline Recurrence/persistence & 3 & 94 & $2.65(0.4 I-17.29)$ & 57.1 & 421 & $8.50(4.20-17.19)$ & 4.0 \\
\hline Mortality & 2 & 32 & $1.38(0.32-5.98)$ & 0 & 113 & 8.14 (2.38-27.89) & 29.7 \\
\hline
\end{tabular}

Abbreviations: TERT, telomerase reverse transcriptase; OR, odds ratio; $\mathrm{Cl}$, confidence interval; $I^{2}$, inconsistency index.

reliable diagnostic approach for thyroid cancer. ${ }^{46}$ Another study conducted by Liu and Xing also achieved brilliant results. ${ }^{47}$ However, almost all of the studies were based on Americans and Europeans, except one from Saudi Arabia. This meta-analysis included five additional studies from Asia, which may be complementary because of the different genetic background among ethnicities.

TERT promoter mutations were exclusively present in FCDTC. Previous researchers propose that TERT promoter mutations usually exist in malignancies originating from terminally differentiated cells with low self-renewing capacity, ${ }^{9}$ while the rapidly renewing tissues have alternative mechanisms for telomere elongation and are less dependent on TERT activation. ${ }^{48}$ In addition, this study showed that TERT promoter mutations were absent in normal tissues or benign lesions; thus they can serve as biomarkers having high specificity for malignancy. However, the diagnostic efficiency may be severely limited by the low prevalence of TERT promoter mutations in DTC. ${ }^{30}$ Liu and Xing and Crescenzi et al, respectively, evaluated the feasibility of TERT promoter mutations in preoperative FNAB and core needle biopsies and found it can improve the diagnostic efficiency for indeterminate nodules. ${ }^{30,32,34}$ A previous study found that $B R A F^{\mathrm{V} 600 \mathrm{E}}$ mutation had no significant value for indeterminate nodules classified as follicular neoplasm/ suspicious for follicular neoplasm (FN/SFN) ${ }^{49}$ In this metaanalysis, the frequencies of TERT promoter mutations in FTC and FVPTC, the main components of malignant FN/SFN nodules, were found to be $17.03 \%$ and $8.09 \%$, respectively. Therefore, TERT promoter mutations may be helpful to diagnose thyroid cancer in FN/SFN nodules.

TERT promoter mutations tended to aggregate in aggressive histological types (ATC, PDTC, and TCPTC) and were significantly associated with high-risk features and adverse outcome. Furthermore, the coexistence of $B R A F^{\mathrm{V} 600 \mathrm{E}}$ and TERT promoter mutations indicated more aggressive tumor and worse prognosis, and the influence of TERT promoter mutations seemed to be more significant than $B R A F^{\mathrm{V} 600 \mathrm{E}}$ mutation. The mechanism underlying the synergetic effect of $B R A F$ and TERT promoter mutations remains uncertain. ${ }^{15,24,25,29,30,39,50}$ Vinagre et al and Bullock et al demonstrated that $B R A F$ and $T E R T$ promoter mutations can increase the expression of each other, ${ }^{17,37}$ which may be achieved by activation of $M A P K$ pathway and regulation of ETS transcriptional factors. ${ }^{50} \mathrm{Li}$ et al found that $\mathrm{C} 250 \mathrm{~T}$ mutation alone was insufficient to drive the transcription of TERT gene and required noncanonical NF- $\kappa B$ signaling for stimulus responsiveness at the same time. ${ }^{51}$ Therefore, the functions of C228T and C250T mutations were distinct, which partially explained the result that no significant association was found between $B R A F$ and C250T mutations. Therefore, TERT promoter mutations can distinguish not only malignancy but also aggressive cases that need more positive therapeutic approach and vigilant monitoring. Some researchers also reported that patients with $T E R T$ promoter mutations tended to suffer from radiotherapeutic resistance, ${ }^{39,52}$ so TERT promoter mutations might also be potential predictors for therapeutic efficiency.

\section{Limitations}

There were some limitations in this meta-analysis. First, most of the studies were retrospectively designed which may cause potential selection bias to better-documented patients and larger tumors since they were more available for collection and analysis. Second, heterogeneity was present in some analyses probably due to confounding factors such as sample size, ethnicity, patients' age, tumor size, sample source, and so on. Besides, most of the aggressive variables are interrelated; so the results should be interpreted cautiously. 


\section{Conclusion}

This meta-analysis confirmed that TERT promoter mutations were more frequent in aggressive histological types of thyroid cancer. And they were likely to present in older patients and males and strongly associated with larger tumor size, extrathyroidal extension, vascular invasion, lymph node metastasis, distant metastasis, advanced tumor stage, disease recurrence/persistence, and mortality. TERT promoter mutations seemed to coexist with $B R A F$ mutation, which contributed to more aggressive tumor and worse prognosis. Therefore, TERT promoter mutations have the potential to serve as biomarkers assisting preoperative diagnosis, risk stratification, prognostic prediction, and individualizing therapeutic option or follow-up design of thyroid cancer.

\section{Acknowledgments}

This study is supported by grants from National Natural Science Foundation of China (No 81202141 and 81272676), the Key Project of Scientific and Technological Innovation of Zhejiang Province (No 2015C03G2010206), National Science and Technology Major Project of the Ministry of Science and Technology of China (No 2013ZX09506015), Medical Science and Technology Project of Zhejiang Province (No 2011ZDA009), and Natural Science Foundation of Zhejiang Province (No Y2110414).

\section{Disclosure}

The authors report no conflicts of interest in this work.

\section{References}

1. Akincilar SC, Unal B, Tergaonkar V. Reactivation of telomerase in cancer. Cell Mol Life Sci. 2016;73(8):1659-1670.

2. Liu Z, Li Q, Li K, et al. Telomerase reverse transcriptase promotes epithelial-mesenchymal transition and stem cell-like traits in cancer cells. Oncogene. 2013;32(36):4203-4213.

3. Daniel M, Peek GW, Tollefsbol TO. Regulation of the human catalytic subunit of telomerase (hTERT). Gene. 2012;498(2):135-146.

4. Ghosh A, Saginc G, Leow SC, et al. Telomerase directly regulates NF-kappaB-dependent transcription. Nat Cell Biol. 2012;14(12): $1270-1281$

5. Low KC, Tergaonkar V. Telomerase: central regulator of all of the hallmarks of cancer. Trends Biochem Sci. 2013;38(9):426-434

6. Horn S, Figl A, Rachakonda PS, et al. TERT promoter mutations in familial and sporadic melanoma. Science. 2013;339(6122):959-961.

7. Huang FW, Hodis E, Xu MJ, Kryukov GV, Chin L, Garraway LA. Highly recurrent TERT promoter mutations in human melanoma. Science. 2013; 339(6122):957-959

8. Huang D-S, Wang Z, He X-J, et al. Recurrent TERT promoter mutations identified in a large-scale study of multiple tumour types are associated with increased TERT expression and telomerase activation. Eur J Cancer. 2015;51(8):969-976.

9. Killela PJ, Reitman ZJ, Jiao Y, et al. TERT promoter mutations occur frequently in gliomas and a subset of tumors derived from cells with low rates of self-renewal. Proc Natl Acad Sci U S A. 2013;110(15): 6021-6026.
10. Kinde I, Munari E, Faraj SF, et al. TERT promoter mutations occur early in urothelial neoplasia and are biomarkers of early disease and disease recurrence in urine. Cancer Res. 2013;73(24):7162-7167.

11. Nault JC, Mallet M, Pilati C, et al. High frequency of telomerase reversetranscriptase promoter somatic mutations in hepatocellular carcinoma and preneoplastic lesions. Nat Commun. 2013;4:2218.

12. Landa I, Ganly I, Chan TA, et al. Frequent somatic TERT promoter mutations in thyroid cancer: higher prevalence in advanced ORMS of the disease. J Clin Endocrinol Metab. 2013;98(9):E1562-E1566.

13. Liu X, Bishop J, Shan Y, et al. Highly prevalent TERT promoter mutations in aggressive thyroid cancers. Endocr Relat Cancer. 2013;20(4): 603-610.

14. Liu T, Wang N, Cao J, et al. The age- and shorter telomere-dependent TERT promoter mutation in follicular thyroid cell-derived carcinomas. Oncogene. 2014;33(42):4978-4984.

15. Liu X, Qu S, Liu R, et al. TERT promoter mutations and their association with BRAF V600E mutation and aggressive clinicopathological characteristics of thyroid cancer. J Clin Endocrinol Metab. 2014;99(6): E1130-E1136.

16. Melo M, Da Rocha AG, Vinagre J, et al. TERT promoter mutations are a major indicator of poor outcome in differentiated thyroid carcinomas. J Clin Endocrinol Metab. 2014;99(5):E754-E765.

17. Vinagre J, Almeida A, Pópulo H, et al. Frequency of TERT promoter mutations in human cancers. Nat Commun. 2013;4:2185.

18. Siegel RL, Miller KD, Jemal A. Cancer statistics, 2015. CA Cancer J Clin. 2015;65:5-29.

19. Weir HK, Thompson TD, Soman A, Moller B, Leadbetter S. The past, present, and future of cancer incidence in the United States: 1975 through 2020. Cancer. 2015;121(11):1827-1837.

20. Xing M. Molecular pathogenesis and mechanisms of thyroid cancer. Nat Rev Cancer. 2013;13(3):184-199.

21. Smallridge RC, Marlow LA, Copland JA. Anaplastic thyroid cancer: molecular pathogenesis and emerging therapies. Endocr Relat Cancer. 2009; 16(1):17-44.

22. Qasem EY, Murugan AK, Al-Hindi HS, et al. TERT promoter mutations in thyroid cancer: a report from a Middle Eastern population. Endocr Relat Cancer. 2015;22(6):901-908.

23. Xing M, Liu R, Liu X, et al. BRAF V600E and TERT promoter mutations cooperatively identify the most aggressive papillary thyroid cancer with highest recurrence. J Clin Oncol. 2014;32(25):2718-2726.

24. George JR, Henderson YC, Williams MD, et al. Association of TERT promoter mutation, but not BRAF mutation, with increased mortality in PTC. J Clin Endocrinol Metab. 2015;100(12):E1550-E1559.

25. Edge SB, Compton CC. The American Joint Committee on Cancer: the 7th edition of the AJCC cancer staging manual and the future of TNM. Ann Surg Oncol. 2010;17(6):1471-1474.

26. Stang A. Critical evaluation of the Newcastle-Ottawa scale for the assessment of the quality of nonrandomized studies in meta-analyses. Eur J Epidemiol. 2010;25(9):603-605.

27. Gandolfi G, Ragazzi M, Frasoldati A, Piana S, Ciarrocchi A, Sancisi V. TERT promoter mutations are associated with distant metastases in papillary thyroid carcinoma. Eur $J$ Endocrinol. 2015;172(4): 403-413.

28. Melo M, Da Rocha AG, Vinagre J, Sobrinho-Simões M, Soares P. Coexistence of TERT promoter and BRAF mutations in papillary thyroid carcinoma: added value in patient prognosis? J Clin Oncol. 2015;33(6):667-668.

29. Ferreira ML, Smeets RJ, Kamper SJ, Ferreira PH, Machado LA. Can we explain heterogeneity among randomized clinical trials of exercise for chronic back pain? A meta-regression analysis of randomized controlled trials. Phys Ther. 2010;90(10):1383-1403.

30. Liu R, Xing M. Diagnostic and prognostic TERT promoter mutations in thyroid fine-needle aspiration biopsy. Endocr Relat Cancer. 2014; 21(5):825-830.

31. Wang N, Liu T, Sofiadis A, et al. TERT promoter mutation as an early genetic event activating telomerase in follicular thyroid adenoma (FTA) and atypical FTA. Cancer. 2014;120(19):2965-2979. 
32. Crescenzi A, Trimboli P, Modica DC, et al. Preoperative assessment of TERT promoter mutation on thyroid core needle biopsies supports diagnosis of malignancy and addresses surgical strategy. Horm Metab Res. 2015;48(3):157-162.

33. De Biase D, Gandolfi G, Ragazzi M, et al. TERT promoter mutations in papillary thyroid microcarcinomas. Thyroid. 2015;25(9):1013-1019.

34. Dettmer MS, Schmitt A, Steinert H, et al. Tall cell papillary thyroid carcinoma: new diagnostic criteria and mutations in BRAF and TERT. Endocr Relat Cancer. 2015;22(3):419-429.

35. Muzza M, Colombo C, Rossi S, et al. Telomerase in differentiated thyroid cancer: promoter mutations, expression and localization. $\mathrm{Mol}$ Cell Endocrinol. 2015;399:288-295.

36. Shi X, Liu R, Qu S, et al. Association of TERT promoter mutation 1,295,228 C > T with BRAF V600E mutation, older patient age, and distant metastasis in anaplastic thyroid cancer. J Clin Endocrinol Metab. 2015;100(4):E632-E637.

37. Bullock M, Ren Y, O'Neill C, et al. TERT promoter mutations are a major indicator of recurrence and death due to papillary thyroid carcinomas. Clin Endocrinol (Oxf). 2016;85(2):283-290.

38. Myung JK, Kwak BK, Lim JA, Lee MC, Kim MJ. Promoter mutations and tumor persistence/recurrence in papillary thyroid cancer. Cancer Res Treat. 2016;48(3):942-947.

39. Bae JS, Kim Y, Jeon S, et al. Clinical utility of TERT promoter mutations and ALK rearrangement in thyroid cancer patients with a high prevalence of the BRAF V600E mutation. Diagn Pathol. 2016; 11(1):21.

40. Jeon MJ, Kim WG, Sim S, et al. Low prevalence of somatic TERT promoter mutations in classic papillary thyroid carcinoma. Endocrinol Metab (Seoul). 2016;31(1):100-104.

41. Jin L, Chen E, Dong S, et al. BRAF and TERT promoter mutations in the aggressiveness of papillary thyroid carcinoma: a study of 653 patients. Oncotarget. 2016;7(14):18346-18355.

42. Sohn SY, Park WY, Shin HT, et al. Highly concordant key genetic alterations in primary tumors and matched distant metastases in differentiated thyroid cancer. Thyroid. 2016;26(5):672-682.
43. Markovina S, Grigsby PW, Schwarz JK, et al. Treatment approach, surveillance, and outcome of well-differentiated thyroid cancer in childhood and adolescence. Thyroid. 2014;24(7):1121-1126.

44. Kim SJ, Park SY, Lee YJ, et al. Risk factors for recurrence after therapeutic lateral neck dissection for primary papillary thyroid cancer. Ann Surg Oncol. 2014;21(6):1884-1890.

45. Ibrahimpasic T, Ghossein R, Carlson DL, et al. Outcomes in patients with poorly differentiated thyroid carcinoma. J Clin Endocrinol Metab. 2014;99(4):1245-1252.

46. De-Tao Y, Kun Y, Run-Qing L, et al. Clinicopathological significance of TERT promoter mutation in papillary thyroid carcinomas: a systematic review and meta-analysis. Clin Endocrinol (Oxf). 2016;85(2): 299-305.

47. Liu R, Xing M. TERT promoter mutations in thyroid cancer. Endocr Relat Cancer. 2016;23(3):R143-R155.

48. Bryan TM, Englezou A, Dalla-Pozza L, Dunham MA, Reddel RR. Evidence for an alternative mechanism for maintaining telomere length in human tumors and tumor-derived cell lines. Nat Med. 1997;3(11): 1271-1274.

49. Su XY, Jiang XX, Xu X, et al. Diagnostic value of BRAFV600Emutation analysis in fine-needle aspiration of thyroid nodules: a metaanalysis. Onco Targets Ther. 2016;9:2495-2509.

50. Pratilas CA, Taylor BS, Ye Q, et al. (V600E)BRAF is associated with disabled feedback inhibition of RAF-MEK signaling and elevated transcriptional output of the pathway. Proc Natl Acad Sci US A. 2009; 106(11):4519-4524.

51. Li Y, Zhou QL, Sun W, et al. Non-canonical NF-kappaB signalling and ETS1/2 cooperatively drive C250T mutant TERT promoter activation. Nat Cell Biol. 2015;17(10):1327-1338.

52. Gao K, Li G, Qu Y, et al. TERT promoter mutations and long telomere length predict poor survival and radiotherapy resistance in gliomas. Oncotarget. 2016;7(8):8712-8725.
OncoTargets and Therapy

\section{Publish your work in this journal}

OncoTargets and Therapy is an international, peer-reviewed, open access journal focusing on the pathological basis of all cancers, potential targets for therapy and treatment protocols employed to improve the management of cancer patients. The journal also focuses on the impact of management programs and new therapeutic agents and protocols on

\section{Dovepress}

patient perspectives such as quality of life, adherence and satisfaction The manuscript management system is completely online and includes a very quick and fair peer-review system, which is all easy to use. Visit http://www.dovepress.com/testimonials.php to read real quotes from published authors. 